\title{
Relationships between clinical scales and binge eating days in adults with moderate to severe binge eating disorder in two Phase III studies
}

This article was published in the following Dove Press journal:

Neuropsychiatric Disease and Treatment

\section{Leslie Citrome' \\ Judith C Kando ${ }^{2}$ \\ Caleb Bliss ${ }^{3}$}

'Department of Psychiatry and Behavioral Sciences, New York Medical College, Valhalla, NY, USA; ${ }^{2}$ Shire, Global Medical Affairs, Lexington, MA, USA; ${ }^{3}$ Shire, Biostatistics, Lexington, MA, USA
Correspondence: Leslie Citrome I I Medical Park Drive, Suite 106, Pomona, NY 10970, USA

Tel +l 845362208 I

Fax + I 8453628745

Email citrome@cnsconsultant.com
Objectives: In two Phase III studies, lisdexamfetamine dimesylate (LDX) reduced binge eating (BE) days/week in adults with moderate to severe binge eating disorder (BED) and was associated with improvement based on the Clinical Global Impressions-Improvement (CGI-I) scale. In this study, post hoc analyses examined the relationships between clinical observations and clinical rating scales in individuals with BED.

Clinical trial registration: NCT01718483 (ClinicalTrials.gov/ct2/show/NCT01718483); NCT01718509 (ClinicalTrials.gov/ct2/show/NCT01718509).

Methods: Two 12-week, double-blind, placebo-controlled studies randomized (1:1) adults meeting Diagnostic and Statistical Manual of Mental Disorders, Fourth Edition, Text Revision, BED criteria and with protocol-defined moderate to severe BED (study 1, N=383; study 2, $\mathrm{N}=390$ ) to placebo or dose-optimized LDX (50 or $70 \mathrm{mg}$ ). Assessments included the number of BE days/week, CGI-Severity (CGI-S) and CGI-I scores, and Yale-Brown Obsessive Compulsive Scale modified for Binge Eating (Y-BOCS-BE) total scores. For these post hoc analyses, data were pooled across studies and treatment arms. Statistical assessments included Spearman correlations and equipercentile linking analyses (ELA). Reported $P$-values are nominal (descriptive and not adjusted for multiplicity).

Results: At baseline, nominally significant correlations with CGI-S scores were reported for BE days/week ( $r=0.374 ; P<0.0001)$ and Y-BOCS-BE total scores $(r=0.319 ; P<0.0001)$. Baseline ELA for CGI-S further characterized this relationship: a CGI-S score of 4 (moderately ill) corresponding to $3.504 \mathrm{BE}$ days/week and a Y-BOCS-BE total score of 18.6. Nominally significant correlations with CGI-I scores were reported for changes from baseline at study endpoint for BE days/week $(r=0.647 ; P<0.0001)$ and Y-BOCS-BE total scores $(r=0.741$; $P<0.0001$ ). ELA for CGI-I scores at study endpoint showed that a CGI-I score of 1 (very much improved) corresponds to a reduction from baseline of 4.504 BE days/week and 19.4 points for Y-BOCS-BE total score.

Conclusion: These post hoc analyses suggest that indices of global disease severity and improvement positively correlate with $\mathrm{BE}$ behavior and with obsessive and compulsive features of BED, measured by the Y-BOCS-BE, supporting the clinical relevance of BED treatment outcomes. Keywords: binge eating days, binge eating disorder, lisdexamfetamine dimesylate, clinical rating scales, Clinical Global Impressions scale, Yale-Brown Obsessive Compulsive Scale modified for Binge Eating

\section{Plain language summary}

Lisdexamfetamine dimesylate (LDX) reduced binge eating days/week, reduced the obsessiveness of binge eating thoughts and compulsiveness of binge eating behavior (based on the Yale-Brown Obsessive Compulsive Scale modified for Binge Eating [Y-BOCS-BE]), and produced global 
disease improvement (based on the Clinical Global ImpressionsImprovement [CGI-I] scale) in adults with moderate to severe binge eating disorder (BED) in Phase III clinical studies. In the present study, pooled, post hoc analyses examined the relationships between clinical observations (binge eating days/week and Y-BOCS-BE total score) and clinical rating scales (CGI-Severity [CGI-S] and CGI-I) in individuals with BED who participated in two LDX clinical studies using equipercentile linking analyses. The findings from these analyses suggest that global disease severity and improvement measures (the CGI-S and CGI-I, respectively) positively correlate with binge eating frequency, with the obsessiveness of binge eating thoughts, and with the compulsiveness of binge eating behavior (measured with Y-BOCS-BE total score). Additionally, binge eating frequency reductions of 3.5-7.0 days/week and Y-BOCS-BE total score reductions of 13.9-36.5 points correspond to CGI-I scores of "very much improved". These findings support the clinical relevance of treatment outcomes in BED.

\section{Introduction}

Lisdexamfetamine dimesylate (LDX) is approved for use in adults with moderate to severe binge eating disorder (BED) in the $\mathrm{US}^{1}$ and other countries. In two large Phase III, randomized, double-blind, placebo-controlled trials, LDX resulted in clinically meaningful and statistically significant reductions in binge eating (BE) days/week compared with placebo in adults with protocol-defined moderate to severe BED. ${ }^{2}$ In these studies, the least squares mean $(95 \% \mathrm{CI})$ treatment differences for the change from baseline BE days/week at weeks 11-12 significantly favored LDX over placebo (study $1:-1.35[-1.70,-1.01]$; study $2:-1.66[-2.04,-1.28]$; both $P<0.001)^{2}$

In these studies, LDX also produced statistically significant improvements on key secondary endpoints that included the Clinical Global Impressions-Improvement (CGI-I) scale and the Yale-Brown Obsessive Compulsive Scale modified for Binge Eating (Y-BOCS-BE). ${ }^{2}$ On the dichotomized CGI-I, the percentage of participants categorized as improved (those with scores of 1 or 2 [much/very much improved]) at week 12/early termination (ET) was greater with LDX than with placebo (study 1: $82.1 \%$ vs $47.3 \%$; study 2 : $86.2 \%$ vs $42.9 \%$; both $P<0.001),{ }^{2}$ resulting in a pooled number needed to treat of 3 (95\% CI: $3-4)$ for LDX versus placebo. ${ }^{3}$ For Y-BOCS-BE total score, the least squares mean $(95 \% \mathrm{CI})$ treatment differences for change from baseline at week 12 significantly favored LDX over placebo (study 1: $-7.40[-8.93,-5.88]$; study 2: $-7.94[-9.51,-6.36]$; both $P<0.001){ }^{2}$

In both studies, ${ }^{2}$ the safety and tolerability profile of LDX was consistent with its well-established profile in individuals with attention-deficit/hyperactivity disorder (ADHD). ${ }^{1}$ Treatment-emergent adverse events reported by $\geq 10 \%$ of participants treated with LDX in both studies were dry mouth, insomnia, and headache. ${ }^{2}$ The observed increases in blood pressure and heart rate ${ }^{2}$ were also consistent with the established safety profile of LDX in ADHD. ${ }^{1}$

Relationships between global clinical disease severity and improvement (measured with the CGI-Severity [CGI-S] and CGI-I scales), the number of BE days/week, and Y-BOCS-BE total score in individuals with BED have not previously been described. Such analyses are key to our understanding of the clinical significance of specific observations (eg, reductions in BE days/week or Y-BOCS-BE total score) in individuals with BED by relating them to standardized global clinical rating scales (ie, CGI-S or CGI-I) that are used in studies of a wide range of psychiatric disorders.

Similar types of analyses have been conducted in other psychiatric conditions, including ADHD, schizophrenia, and panic disorder. ${ }^{4-7}$ In an analysis of two LDX studies in individuals with ADHD (one in children ${ }^{8}$ and one in adults $^{9}$ ), the relationship between ADHD Rating Scale, Version 4 (ADHD-RS-IV) total scores and CGI-S and CGI-I scores was examined. ${ }^{4}$ This post hoc analysis found that ADHD-RS-IV total score changes from baseline of $\sim 8-10$ points corresponded to a 1-point improvement in CGI-S score and that changes of 10-15 points corresponded to a 1-point improvement in CGI-I score. ${ }^{4}$ In an analysis of 14 clinical trials of acutely ill individuals with schizophrenia, ${ }^{7}$ relationships between the Brief Psychiatric Rating Scale (BPRS), Positive and Negative Syndrome Scale (PANSS), and CGI-I scores were examined. This analysis demonstrated that 10-point reductions on the BPRS and 15-point reductions on the PANSS corresponded to a CGI-I rating of minimally improved and a CGI-S score change of 1 point. $^{7}$ Taken together, these analyses support the concept that the CGI is a valid estimate of psychopathology and clinically relevant disease improvement, thereby offering the practicing clinician a tool to track global disease improvement during treatment, as has previously been suggested..$^{10,11}$

The objective of this report was to further understand the relationships between clinical observations of $\mathrm{BE}$, the number of BE days/week and Y-BOCS-BE total score, and the CGI-S at baseline and the CGI-I at the end of treatment in adults with BED.

\section{Methods}

The design and methodology of the two Phase III BED studies included in these post hoc analyses has previously 
been described in detail ${ }^{2}$ a summary is provided in the following text.

\section{Study design and treatment}

These randomized, placebo-controlled, parallel-group, multicenter studies (ClinicalTrials.gov registry numbers: NCT01718483 and NCT01718509) were conducted using the same design and methods. Each study included three phases: a 2-week screening phase, a 12-week double-blind phase (dose-optimization period, 4 weeks; dose-maintenance period, 8 weeks), and a follow-up visit. After screening, participants were randomized 1:1 to placebo or dose-optimized LDX (50 or $70 \mathrm{mg}$ ) for 12 weeks. Treatment with LDX was started at $30 \mathrm{mg}$ during week 1 and increased to $50 \mathrm{mg}$ during week 2. Increases to $70 \mathrm{mg} \mathrm{LDX}$, based on tolerability and clinical need, occurred during weeks 3 and 4 . A one-time decrease to $50 \mathrm{mg}$ LDX was permitted during week 3 based on participant tolerability. The optimized LDX dosage (50 or $70 \mathrm{mg}$ ) was maintained during weeks 4-12; participants requiring a dosage reduction during the dose-maintenance phase were discontinued. A follow-up visit occurred 1 week after the week 12/ET visit to assess safety.

Each study was approved by ethics committees (Box S1). Both studies were conducted in accordance with International Conference on Harmonization of Good Clinical Practice and the principles of the Declaration of Helsinki. All participants were required to provide written, informed consent before entering a study.

\section{Participants}

Eligible participants were men or nonpregnant women (aged 18-55 years) meeting Diagnostic and Statistical Manual of Mental Disorders, Fourth Edition, Text Revision (DSMIV-TR) BED criteria, confirmed by the eating disorders module of the Structured Clinical Interview for the DSM-IV Axis I Disorders and the Eating Disorder Examination Questionnaire, and having protocol-defined moderate to severe BED ( $\geq 3 \mathrm{BE}$ days/week for 14 days before baseline and a CGI-S score $\geq 4$ at screening and baseline) and a body mass index (BMI) of $18-45 \mathrm{~kg} / \mathrm{m}^{2}$. Full exclusion criteria have been reported previously. ${ }^{2}$ Key exclusion criteria included current anorexia nervosa or bulimia nervosa; a comorbid psychiatric disorder controlled with prohibited medications or uncontrolled and associated with significant symptoms or any condition that could confound assessments; having received psychotherapy or weight loss support for BED within 3 months of screening; being considered a suicide risk by the investigator, previously attempting suicide, or currently demonstrating active suicidal ideation; having a history of cardiovascular issues or moderate or severe hypertension; and having a lifetime amphetamine or stimulant abuse history, recent substance abuse or dependence history, or intolerance or hypersensitivity to LDX or related compounds. Excluded medications included benzodiazepines, antidepressants, antipsychotics, anxiolytics, clonidine, guanfacine, investigational compounds, monoamine oxidase inhibitors, narcotics, sedatives/ sedative hypnotics, weight loss therapies (within 30 days of screening); sympathomimetics and appetite suppressants (within 6 months of screening); and cough/cold suppressants containing stimulants/sympathomimetic agents, herbal preparations, melatonin, sedating antihistamines (within 7 days of screening). In addition, any psychoactive medication used within five half-lives of screening was exclusionary.

\section{Endpoints}

Efficacy endpoints included in these post hoc analyses included BE days/week, CGI-S and CGI-I scores, and Y-BOCS-BE total score. BE days/week (prespecified primary efficacy endpoint) was captured daily via self-reported diaries. The CGI-S assessed global disease severity at baseline on a 7-point scale (range: 1 [normal, not at all ill] to 7 [among the most extremely ill]). ${ }^{12}$ The CGI-I (prespecified key secondary endpoint), a measure of global improvement in disease severity ${ }^{12}$ relative to baseline, was assessed on a 7-point scale (range: 1 [very much improved] to 7 [very much worse]). The Y-BOCS-BE ${ }^{13}$ (prespecified key secondary endpoint), which is a modified version of the Y-BOCS, ${ }^{14}$ assessed the obsessiveness of BE thoughts and compulsiveness of BE behavior. Y-BOCS-BE total score ranges from 0 to 40 , with higher scores indicating more severe symptoms.

\section{Data presentation and statistical analyses}

For the post hoc analyses described herein, data at baseline or study endpoint (weeks 11-12 for BE days/week; week 12/ET for CGI-I; week 12 for Y-BOCS-BE total score) were pooled across studies. Data are reported for each treatment arm and for the overall population. Participants were from the full analysis set (FAS; those taking $\geq 1$ study drug dose and having $\geq 1$ postbaseline assessment for the number of $\mathrm{BE}$ days/week) of each study with non-missing values for both variables in each relationship.

Descriptive statistics for BE days/week and Y-BOCS-BE total score are presented by CGI-S and CGI-I scores. Spearman correlations assessed relationships at baseline (CGI-S score and the number of BE days/week; CGI-S score and 
Y-BOCS-BE total score) and at study endpoint (CGI-I score at week 12/ET and the number of BE days/week at weeks 11-12; CGI-I score at week 12/ET and the change from baseline in the number of BE days/week at weeks 11-12; CGI-I score at week 12/ET and Y-BOCS-BE total score at week 12; CGI-I score at week 12/ET and the change in Y-BOCS-BE total score at week 12). Reported $P$-values are nominal (ie, not adjusted for multiplicity) and are presented for descriptive purposes only.

Equipercentile linking analyses were conducted as previously described by Goodman et al. ${ }^{4}$ These analyses identified scores on different measures with the same percentile rank. First, a percentile rank function for each variable was generated. For each function, respective scores on two measures were plotted as $\mathrm{X}, \mathrm{Y}$ pair values based on each variable having the same percentile rank. Percentile rank functions were calculated for relationships at baseline (CGI-S score and the number of BE days/week; CGI-S score and Y-BOCS-BE total score) and at study endpoint (CGI-I score at week 12/ET and the change from baseline in the number of BE days/week at weeks 11-12; CGI-I score at week 12/ET and the change in Y-BOCS-BE total score at week 12). The equipercentile

\section{A}
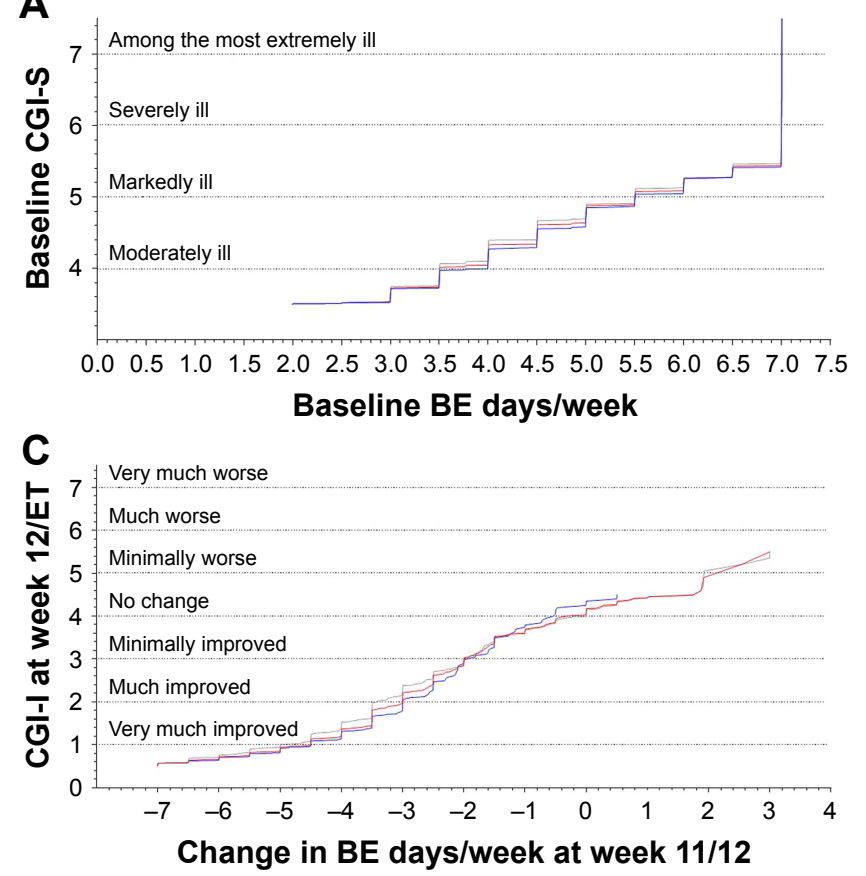

linking function requires that both variables be continuous. To apply this method in the current analyses, CGI-S, CGI-I, and Y-BOCS-BE scores were considered piecewise continuous in the range $\mathrm{X}-0.5$ to $\mathrm{X}+0.5$, and $\mathrm{BE}$ days/week values were considered piecewise continuous in the range $\mathrm{X}-0.005$ to $\mathrm{X}+0.005$ (as shown in Figure 1). Therefore, all reported values are understood to encompass a range. It is important to emphasize that this technique did not compare absolute scores between measures for individual participants. Rather, it identified scores for clinical observations (BE days/week or Y-BOCS-BE) having the same percentile rank on a clinical scale (CGI-S or CGI-I). Individual participant scores on specific items on the Y-BOCS-BE were not taken into account.

\section{Results}

\section{Participant disposition and demographics}

The pooled FAS in this analysis included 360 participants randomized to placebo and 364 randomized to LDX. Participant demographic and clinical characteristics are briefly summarized in Table 1. Most participants were female, white, and obese (BMI range: $18.5-45.2 \mathrm{~kg} / \mathrm{m}^{2}$ ). The mean number of BE days/week, mean Y-BOCS-BE total score,

B
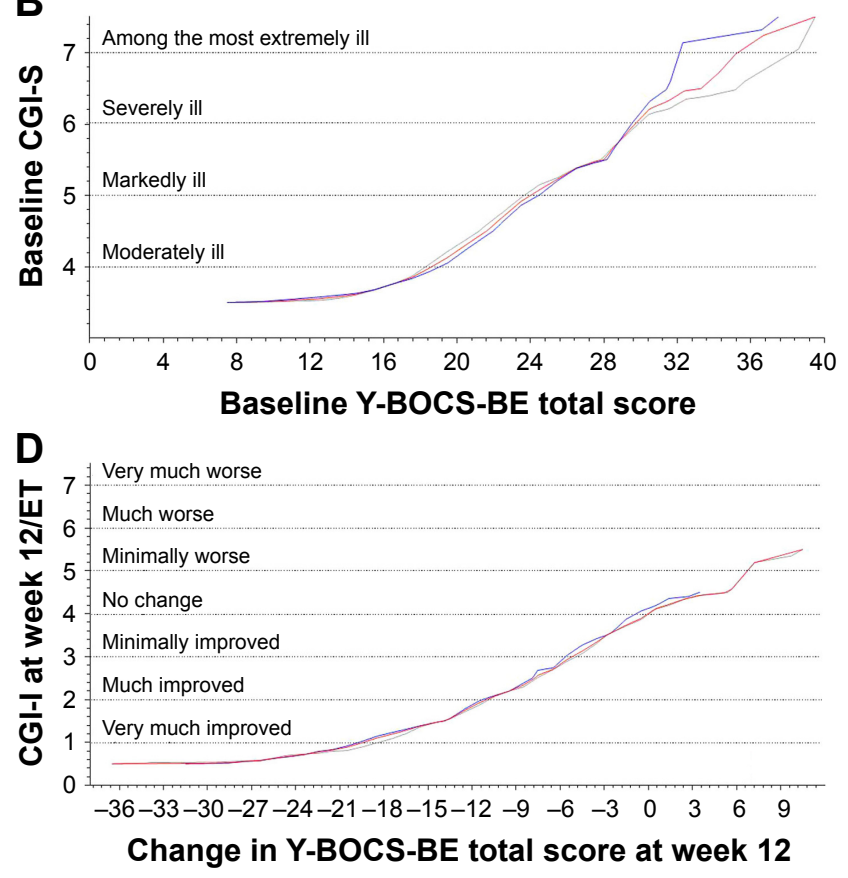

- Overall - PBO - LDX

Figure I Equipercentile linking functions ${ }^{\mathrm{a}}$ at baseline (A and $\left.\mathbf{B}\right)$ and for change from baseline (C and $\left.\mathbf{D}\right)$, pooled full analysis set.

Notes: ${ }^{\mathrm{T}}$ The equipercentile linking function requires that both variables be continuous. To apply this method, scores for CGI-S, CGI-I, and Y-BOCS-BE were considered piecewise continuous ranging from $X-0.5$ to $X+0.5$, and scores for binge eating days/week were considered piecewise continuous ranging from $X-0.005$ to $X+0.005$. Therefore, all values are understood to encompass a range.

Abbreviations: BE, binge eating; CGI-I, Clinical Global Impressions-Improvement; CGI-S, Clinical Global Impressions-Severity; ET, early termination; LDX, lisdexamfetamine dimesylate; PBO, placebo; Y-BOCS-BE, Yale-Brown Obsessive Compulsive Scale modified for Binge Eating. 
Table I Baseline demographic and clinical characteristics, pooled full analysis set

\begin{tabular}{|c|c|c|c|}
\hline & $\begin{array}{l}\text { Overall } \\
(n=724)\end{array}$ & $\begin{array}{l}\text { PBO } \\
(n=360)\end{array}$ & $\begin{array}{l}\text { LDX } \\
(n=364)\end{array}$ \\
\hline Mean \pm SD age, years & $38.0 \pm 10.18$ & $38.1 \pm 10.12$ & $37.9 \pm 10.25$ \\
\hline Female, n (\%) & $627(86.6)$ & $310(86.1)$ & $317(87.1)$ \\
\hline White, $n(\%)$ & $550(76.0)$ & $274(76.1)$ & $276(75.8)$ \\
\hline $\begin{array}{l}\text { Mean } \pm \text { SD weight, } \mathrm{kg} \\
\mathrm{BMl}^{\mathrm{a}}\end{array}$ & $93.67 \pm 20.223$ & $93.00 \pm 19.832$ & $94.33 \pm 20.608$ \\
\hline Mean $\pm \mathrm{SD}, \mathrm{kg} / \mathrm{m}^{2}$ & $33.52 \pm 6.254$ & $33.32 \pm 6.292$ & $33.72 \pm 6.218$ \\
\hline $\begin{array}{l}\text { Obese (BMI } \\
\left.\geq 30 \mathrm{~kg} / \mathrm{m}^{2}\right), \mathrm{n}(\%)\end{array}$ & $495(68.4)$ & $247(68.6)$ & $248(68.1)$ \\
\hline $\begin{array}{l}\text { Mean } \pm \text { SD binge } \\
\text { days/week } \\
\text { CGI-S, }{ }^{b} \text { (\%) }\end{array}$ & $4.72 \pm 1.296$ & $4.71 \pm 1.321$ & $4.72 \pm 1.272$ \\
\hline Moderately ill & $381(52.6)$ & $183(50.8)$ & $198(54.4)$ \\
\hline Markedly ill & $280(38.7)$ & I4I (39.2) & $139(38.2)$ \\
\hline Severely ill & $56(7.7)$ & $34(9.4)$ & $22(6.0)$ \\
\hline $\begin{array}{l}\text { Among the most } \\
\text { extremely ill }\end{array}$ & $7(1.0)$ & $2(0.6)$ & $5(1.4)$ \\
\hline $\begin{array}{l}\text { Mean } \pm \text { SD Y-BOCS- } \\
\text { BE total score }\end{array}$ & $21.49 \pm 4.724$ & $21.52 \pm 4.785$ & $21.46 \pm 4.669$ \\
\hline
\end{tabular}

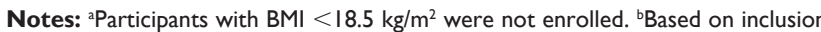
criteria, a CGI-S score $\geq 4$ (at least moderately ill) was required for study eligibility. 'Based on $n=72$ I for the overall population, $n=359$ for placebo and $n=362$ for LDX. Abbreviations: $\mathrm{BE}$, binge eating; BMI, body mass index; CGI-S, Clinical Global Impressions-Severity; LDX, lisdexamfetamine dimesylate; PBO, placebo; Y-BOCSBE, Yale-Brown Obsessive Compulsive Scale modified for Binge Eating.

and distribution of CGI-S scores at baseline were comparable across treatment groups.

\section{Score distributions}

Baseline BE days/week and Y-BOCS-BE total scores by CGI-S score, values at the end of the study by CGI-I score, and changes from baseline at the end of the study by CGI-I score are summarized in Table 2.

\section{Baseline relationships}

Nominally significant correlations with CGI-S scores were reported for the number of BE days/week $(r=0.374$; $P<0.0001)$ and $\mathrm{Y}$-BOCS-BE total score $(r=0.319 ; P<0.0001$; Table 2) in the overall population, with a higher number of BE days/week and higher Y-BOCS-BE total scores at baseline being associated with higher baseline CGI-S scores. For a CGI-S score of 4 (moderately ill) at baseline, the mean \pm SD number of BE days/week at baseline was $4.27 \pm 1.130$ and the mean \pm SD Y-BOCS-BE total score was $20.06 \pm 3.967$ in the overall population (Table 2).

Equipercentile linking functions for CGI-S scores and BE days/week and Y-BOCS-BE total score at baseline are depicted in Figure 1A and B. In the overall population, a CGI-S score of 4 (moderately ill) corresponded to 3.504 (range: 1.995-4.501) BE days/week and a Y-BOCS-BE total score of 18.6 (range: 7.5-21.6; Table 3).

\section{Change from baseline relationships}

Nominally significant correlations with CGI-I scores were reported for the number of BE days/week $(r=0.795$; $P<0.0001$ ), for the change from baseline in BE days/week at weeks $11-12(r=0.647 ; P<0.0001)$, for Y-BOCS-BE total score at week $12(r=0.797 ; P<0.0001)$, and for the change from baseline in Y-BOCS-BE total score at week 12 ( $r=0.741 ; P<0.0001$; Table 2$)$ in the overall population; a lower number of $\mathrm{BE}$ days/week and greater reductions from baseline were associated with greater improvement as measured by the CGI-I. For the placebo and LDX treatment groups, respectively, nominally significant correlations with CGI-I scores were reported for the number of BE days/week ( $r=0.764$ and $r=0.668$; both $P<0.0001$ ), for the change from baseline in BE days/week at weeks 11-12 ( $r=0.695$ and $r=0.391$; both $P<0.0001)$, for Y-BOCS-BE total score at week 12 ( $r=0.726$ and $r=0.671$; both $P<0.0001)$, and for the change from baseline in Y-BOCS-BE total score at week 12 ( $r=0.695$ and $r=0.560$; both $P<0.0001$ ).

For a CGI-I score of 1 (very much improved) at week 12/ET, the mean \pm SD number of BE days/week at weeks $11-12$ was $0.26 \pm 0.523$ in the overall population, $0.33 \pm 0.620$ in the placebo treatment group, and $0.23 \pm 0.481$ in the LDX treatment group; the mean $\pm \mathrm{SD}$ change in $\mathrm{BE}$ days/week from baseline was $-4.36 \pm 1.384$ in the overall population, $-4.27 \pm 1.522$ in the placebo treatment group, and $-4.39 \pm 1.331$ in the LDX treatment group (Table 2). For Y-BOCS-BE total score, the mean \pm SD total score at week 12 was $3.05 \pm 3.951$ in the overall population, $4.47 \pm 4.585$ in the placebo treatment group, and $2.53 \pm 3.565$ in the LDX treatment group in participants with a CGI-I score of 1 at week $12 / \mathrm{ET}$; the mean $\pm \mathrm{SD}$ change from baseline in total score was $-18.39 \pm 6.129$ in the overall population, $-17.35 \pm 7.189$ in the placebo treatment group, and $-18.77 \pm 5.661$ in the LDX treatment group (Table 2).

Equipercentile linking functions between CGI-I scores and changes in the number of BE days/week and Y-BOCS-BE total score are depicted in Figure 1C and D. In the overall population, a CGI-I score of 1 (very much improved) at week 12/ET corresponded to a change of -4.504 (range: -7.005 to -3.502; Table 3) from baseline in the number of BE days/ week at weeks 11-12. For the placebo and LDX treatment groups, respectively, a CGI-I score of 1 at week 12/ET corresponded to changes of -4.996 (range: -7.005 to -3.997 ) and -4.502 (range: -7.005 to -3.498 ) from baseline in 
Table 2 Binge eating days/week and Y-BOCS-BE total score distribution by CGI-S and CGI-I scores, pooled full analysis set

\begin{tabular}{|c|c|c|c|c|c|c|}
\hline & \multicolumn{2}{|c|}{ Overall } & \multicolumn{2}{|c|}{ PBO } & \multicolumn{2}{|c|}{ LDX } \\
\hline & $\mathbf{n}$ & Mean \pm SD & $\mathbf{n}$ & Mean \pm SD & $\mathbf{n}$ & Mean \pm SD \\
\hline & \multicolumn{6}{|c|}{ Baseline values } \\
\hline CGI-S at baseline & \multicolumn{6}{|c|}{ Binge eating days/week } \\
\hline Moderately ill (CGI-S =4) & 381 & $4.27 \pm 1.130$ & 183 & $4.20 \pm 1.144$ & 198 & $4.33 \pm 1.117$ \\
\hline Markedly ill (CGI-S =5) & 280 & $5.12 \pm 1.273$ & $14 \mid$ & $5.18 \pm 1.300$ & 139 & $5.06 \pm 1.246$ \\
\hline Severely ill (CGI-S =6) & 56 & $5.56 \pm 1.245$ & 34 & $5.42 \pm 1.215$ & 22 & $5.77 \pm 1.288$ \\
\hline Among the most extremely ill ( $\mathrm{CGI}-\mathrm{S}=7$ ) & 7 & $6.07 \pm 1.592$ & 2 & $5.25 \pm 2.475$ & 5 & $6.40 \pm 1.342$ \\
\hline Spearman correlations & \multicolumn{2}{|c|}{$\mathrm{n}=724 ; r=0.374 ; P<0.0001$} & \multicolumn{2}{|c|}{$\mathrm{n}=360 ; r=0.389 ; \mathrm{P}<0.000 \mathrm{I}$} & \multicolumn{2}{|c|}{$\mathrm{n}=364 ; r=0.359 ; P<0.0001$} \\
\hline CGI-S at baseline & \multicolumn{4}{|c|}{ Y-BOCS-BE total score } & & \\
\hline Moderately ill $(\mathrm{CGI}-\mathrm{S}=4)$ & 380 & $20.06 \pm 3.967$ & 183 & $20.05 \pm 3.738$ & 197 & $20.06 \pm 4.179$ \\
\hline Markedly ill (CGI-S =5) & 278 & $22.72 \pm 4.687$ & 140 & $22.48 \pm 4.716$ & 138 & $22.96 \pm 4.662$ \\
\hline Severely ill (CGI-S =6) & 56 & $24.46 \pm 5.818$ & 34 & $24.82 \pm 6.379$ & 22 & $23.91 \pm 4.918$ \\
\hline Among the most extremely ill ( $\mathrm{CGI}-\mathrm{S}=7$ ) & 7 & $27.00 \pm 6.429$ & 2 & $32.50 \pm 9.192$ & 5 & $24.80 \pm 4.438$ \\
\hline \multirow[t]{2}{*}{ Spearman correlations } & \multicolumn{2}{|c|}{$\mathrm{n}=721 ; r=0.319 ; P<0.0001$} & \multicolumn{2}{|c|}{$\mathrm{n}=359 ; r=0.318 ; P<0.0001$} & \multicolumn{2}{|c|}{$\mathrm{n}=362 ; r=0.319 ; P<0.0001$} \\
\hline & \multicolumn{6}{|c|}{ End of study values } \\
\hline CGI-I at week I2/ET & \multicolumn{6}{|c|}{ Binge eating days/week (weeks II-I2) } \\
\hline Very much improved $(\mathrm{CGI}-\mathrm{I}=\mathrm{I})$ & 270 & $0.26 \pm 0.523$ & 73 & $0.33 \pm 0.620$ & 197 & $0.23 \pm 0.48$ I \\
\hline Much improved (CGI-I =2) & 130 & $1.33 \pm 1.198$ & 62 & $1.44 \pm 1.198$ & 68 & $1.24 \pm 1.199$ \\
\hline Minimally improved $(\mathrm{CGI}-\mathrm{I}=3)$ & 87 & $2.66 \pm 1.627$ & 63 & $2.8 I \pm 1.726$ & 24 & $2.26 \pm 1.280$ \\
\hline No change $(C G I-I=4)$ & 114 & $3.98 \pm 1.835$ & 99 & $4.05 \pm 1.816$ & 15 & $3.5 I \pm 1.958$ \\
\hline Minimally worse $(\mathrm{CGI}-\mathrm{I}=5)$ & 5 & $5.63 \pm 1.488$ & 5 & $5.63 \pm 1.488$ & 0 & - \\
\hline Spearman correlations & \multicolumn{2}{|c|}{$\mathrm{n}=606 ; r=0.795 ; P<0.0001$} & \multicolumn{2}{|c|}{$\mathrm{n}=302 ; r=0.764 ; P<0.000 I$} & \multicolumn{2}{|c|}{$\mathrm{n}=304 ; r=0.668 ; P<0.0001$} \\
\hline CGI-I at week I 2/ET & \multicolumn{4}{|c|}{ Y-BOCS-BE total score (week I 2) } & & \\
\hline Very much improved $(\mathrm{CGI}-\mathrm{I}=\mathrm{I})$ & 276 & $3.05 \pm 3.951$ & 74 & $4.47 \pm 4.585$ & 202 & $2.53 \pm 3.565$ \\
\hline Much improved (CGI-I =2) & $|3|$ & $9.86 \pm 5.320$ & 62 & $11.16 \pm 5.463$ & 69 & $8.70 \pm 4.942$ \\
\hline Minimally improved $(\mathrm{CGI}-\mathrm{I}=3)$ & 89 & $15.78 \pm 6.376$ & 63 & $17.27 \pm 6.120$ & 26 & $12.15 \pm 5.562$ \\
\hline No change $(\mathrm{CGI}-\mathrm{I}=4)$ & 118 & $19.34 \pm 5.735$ & 102 & $19.49 \pm 5.712$ & 16 & $18.38 \pm 5.976$ \\
\hline Minimally worse $(\mathrm{CGI}-\mathrm{I}=5)$ & 5 & $18.60 \pm 2.702$ & 5 & $18.60 \pm 2.702$ & 0 & - \\
\hline \multirow[t]{2}{*}{ Spearman correlations } & \multicolumn{2}{|c|}{$\mathrm{n}=619 ; r=0.797 ; P<0.0001$} & \multicolumn{2}{|c|}{$\mathrm{n}=306 ; r=0.726 ; P<0.0001$} & \multicolumn{2}{|c|}{$\mathrm{n}=313 ; r=0.671 ; P<0.0001$} \\
\hline & Chat & om baseline $v$ & & & & \\
\hline CGI-I at week I2/ET & Bing & ing days/week & s II- & & & \\
\hline Very much improved $(\mathrm{CGI}-\mathrm{I}=\mathrm{I})$ & 270 & $-4.36 \pm 1.384$ & 73 & $-4.27 \pm 1.522$ & 197 & $-4.39 \pm 1.33 \mid$ \\
\hline Much improved (CGI-I =2) & 130 & $-3.4 I \pm 1.503$ & 62 & $-3.30 \pm 1.540$ & 68 & $-3.5 \mathrm{I} \pm \mathrm{I} .472$ \\
\hline Minimally improved $(\mathrm{CGI}-\mathrm{I}=3)$ & 87 & $-2.10 \pm 1.512$ & 63 & $-1.93 \pm 1.622$ & 24 & $-2.53 \pm 1.085$ \\
\hline No change $(C G I-I=4)$ & 114 & $-0.88 \pm 1.739$ & 99 & $-0.68 \pm 1.591$ & 15 & $-2.16 \pm 2.158$ \\
\hline Minimally worse $(\mathrm{CGI}-\mathrm{I}=5)$ & 5 & $-0.47 \pm 1.980$ & 5 & $-0.47 \pm 1.980$ & 0 & - \\
\hline Spearman correlations & $\mathrm{n}=60$ & $647 ; P<0.0001$ & $\mathrm{n}=30$ & $695 ; P<0.0001$ & $\mathrm{n}=30$ & $.391 ; P<0.0001$ \\
\hline CGI-I at week I 2/ET & $\mathbf{Y}-\mathbf{B C}$ & $3 E$ total score & 12) & & & \\
\hline Very much improved $(\mathrm{CGI}-\mathrm{I}=\mathrm{I})$ & 275 & $-18.39 \pm 6.129$ & 74 & $-17.35 \pm 7.189$ & 201 & $-|8.77 \pm 5.66|$ \\
\hline Much improved (CGI-I =2) & 130 & $-11.56 \pm 6.258$ & 62 & $-9.94 \pm 6.222$ & 68 & $-13.04 \pm 5.956$ \\
\hline Minimally improved $(\mathrm{CGI}-\mathrm{I}=3)$ & 89 & $-5.24 \pm 5.88 \mathrm{I}$ & 63 & $-4.1 I \pm 5.728$ & 26 & $-7.96 \pm 5.429$ \\
\hline No change $(\mathrm{CGI}-\mathrm{I}=4)$ & 118 & $-2.69 \pm 5.328$ & 102 & $-2.10 \pm 4.948$ & 16 & $-6.44 \pm 6.261$ \\
\hline Minimally worse $(\mathrm{CGI}-\mathrm{I}=5)$ & 5 & $-0.40 \pm 1.673$ & 5 & $-0.40 \pm 1.673$ & 0 & - \\
\hline Spearman correlations & $n=61$ & $74 I ; P<0.000 I$ & $\mathrm{n}=30$ & $695 ; P<0.000$ I & $n=31$ & $.560 ; P<0.0001$ \\
\hline
\end{tabular}

Abbreviations: CGI-I, Clinical Global Impressions-Improvement; CGI-S, Clinical Global Impressions-Severity; ET, early termination; LDX, lisdexamfetamine dimesylate; PBO, placebo; Y-BOCS-BE, Yale-Brown Obsessive Compulsive Scale modified for Binge Eating.

$\mathrm{BE}$ days/week at weeks 11-12. In the overall population, a CGI-I score of 1 at week 12/ET corresponded to a change of -19.4 (range: -36.5 to -13.9 ; Table 3) from baseline in Y-BOCS-BE total score at week 12. For the placebo and LDX treatment groups, respectively, a CGI-I score of 1 at week 12/ET corresponded to changes of -18.4 (range: -36.5 to -14.1 ) and -19.7 (range: -31.5 to -13.9 ) from baseline in Y-BOCS-BE total score at week 12.

\section{Discussion}

These post hoc analyses indicate that measures of global disease severity and improvement (based on CGI-S and 
Table 3 Ranges derived from the equipercentile linking function, pooled full analysis set

\begin{tabular}{|c|c|c|c|}
\hline & Overall & PBO & LDX \\
\hline & $\begin{array}{l}\text { Corresponding score } \\
\text { (range) }\end{array}$ & $\begin{array}{l}\text { Corresponding score } \\
\text { (range) }\end{array}$ & $\begin{array}{l}\text { Corresponding score } \\
\text { (range) }\end{array}$ \\
\hline & \multicolumn{3}{|l|}{ Binge eating days/week ${ }^{\mathrm{a}}$} \\
\hline CGI-S at baseline ${ }^{b}$ & $\mathrm{n}=724$ & $n=360$ & $n=364$ \\
\hline Moderately ill (CGI-S =4) & $3.504(1.995,4.50 I)$ & $3.503(1.995,4.499)$ & $3.995(1.995,4.503)$ \\
\hline Markedly ill (CGI-S =5) & $5.501(4.502,6.997)$ & $5.499(4.500,6.996)$ & $5.503(4.503,6.998)$ \\
\hline Severely ill/extremely ill (CGI-S $=6$ or 7$)^{c}$ & $7.001 / 7.005(6.997,7.005)$ & $7.000 / 7.005(6.996,7.005)$ & $7.001 / 7.004(6.998,7.005)$ \\
\hline CGI-I at week I 2/ET & $n=606$ & $\mathrm{n}=302$ & $n=304$ \\
\hline Very much improved $(C G I-I=I)$ & $-4.504(-7.005,-3.502)$ & $-4.996(-7.005,-3.997)$ & $-4.502(-7.005,-3.498)$ \\
\hline Much improved (CGI-I =2) & $-3.003(-3.502,-2.500)$ & $-3.420(-3.996,-2.628)$ & $-2.997(-3.498,-2.310)$ \\
\hline Minimally improved (CGI-I=3) & $-1.996(-2.499,-1.497)$ & $-1.997(-2.624,-1.498)$ & $-1.995(-2.303,-1.495)$ \\
\hline \multirow[t]{2}{*}{ Not improved $(\mathrm{CGI}-\mathrm{I}=4 \text { or } 5)^{d}$} & $-0.305 / 1.922(-1.496,3.005)$ & $-0.004 / 1.922(-1.497,3.005)$ & $-0.540 / \mathrm{NA}(-1.269,0.505)$ \\
\hline & \multicolumn{3}{|l|}{ Y-BOCS-BE total score ${ }^{\mathrm{a}}$} \\
\hline CGI-S at baseline ${ }^{b}$ & $n=721$ & $n=359$ & $n=362$ \\
\hline Moderately ill (CGI-S =4) & $18.6(7.5,21.6)$ & $18.3(7.5,21.2)$ & 19.1 (7.5, 22.0) \\
\hline Markedly ill (CGI-S =5) & $24.0(21.6,28.0)$ & $23.7(21.2,27.7)$ & $24.4(22.0,28.2)$ \\
\hline Severely ill/extremely ill (CGI-S $=6$ or 7$)^{c}$ & $29.7 / 35.2(28.1,39.5)$ & $29.9 / 36.5(27.8,39.5)$ & $29.5 / 32.1(28.3,37.5)$ \\
\hline CGI-I at week I 2/ET & $n=617$ & $n=306$ & $n=311$ \\
\hline Very much improved $(C G I-I=I)$ & $-19.4(-36.5,-13.9)$ & $-18.4(-36.5,-14.1)$ & $-19.7(-31.5,-13.9)$ \\
\hline Much improved (CGI-I =2) & $-11.0(-13.8,-7.8)$ & $-10.8(-14.0,-7.6)$ & $-11.3(-13.8,-7.9)$ \\
\hline Minimally improved $(\mathrm{CGI}-\mathrm{I}=3)$ & $-5.2(-7.7,-2.9)$ & $-4.9(-7.6,-2.8)$ & $-5.6(-7.9,-2.9)$ \\
\hline Not improved $(\mathrm{CGI}-\mathrm{I}=4 \text { or } 5)^{\mathrm{d}}$ & $-0.0 / 6.7(-2.8,10.5)$ & $0.1 / 6.7(-2.8,10.5)$ & $-0.8 / \mathrm{NA}(-2.7,3.5)$ \\
\hline
\end{tabular}

Notes: ${ }^{B}$ Baseline values for CGI-S analysis; values at week II/I2 for binge days/week and week 12 for Y-BOCS-BE total score for CGI-I analysis. ${ }^{\circ}$ Estimates for CGI-S scores of I (normal, not at all ill), 2 (borderline mentally ill), and 3 (mildly ill) could not be determined because inclusion criteria for the studies required a CGI-S score $\geq 4$. ${ }^{\text {FFor }}$ the current analyses, scores of 6 (severely ill) or 7 (most extremely ill) on the CGI-S were merged because of limited sample size. ${ }^{\text {d} F o r ~ t h e ~ c u r r e n t ~ a n a l y s e s, ~ s c o r e s ~ o f ~} 4$ or 5 (no participants had scores of 6 or 7) on the CGI-I were merged because of limited sample size and defined as "not improved".

Abbreviations: CGI-I, Clinical Global Impressions-Improvement; CGI-S, Clinical Global Impressions-Severity; ET, early termination; LDX, lisdexamfetamine dimesylate; NA, not available; PBO, placebo; Y-BOCS-BE, Yale-Brown Obsessive Compulsive Scale modified for Binge Eating.

CGI-I) positively correlate with BE frequency (reflected by the number of BE days/week) and with the obsessive and compulsive features of BED (reflected by Y-BOCS-BE total score). These findings in individuals with BED are consistent with those reported in analogous analyses conducted with individuals with ADHD, schizophrenia, and panic disorder. $^{4-7}$

These findings provide a benchmark for the interpretation of the clinical relevance of values for BE days/week and Y-BOCS-BE total score (in regard to global disease severity based on CGI-S scores) and reductions in BE days/week and Y-BOCS-BE total scores (in regard to global clinical improvement based on CGI-I scores). At baseline, values for the number of BE days/week and Y-BOCS-BE total score that corresponded to "moderately ill" on the CGI-S were 3.504 and 18.6, respectively. The value of 18.6 for $\mathrm{Y}$-BOCS-BE total score is consistent with the suggestion that Y-BOCS-BE total scores in the range 16-23 correspond to the moderate symptom range. ${ }^{15}$ At the end of the study, reductions in the number of $\mathrm{BE}$ days/week and in Y-BOCS-BE total score corresponding to "very much improved" on the CGI-I were -4.504 and -19.4 , respectively.
The Y-BOCS-BE changes associated with "minimally improved" (-5.2) to "very much improved" (-19.4) on the CGI-I are roughly consistent with the reported minimally clinically important change of -4 to -17 for the Y-BOCSBE. ${ }^{13}$ Although multiple studies have reported concurrent reductions in BE frequency, Y-BOCS-BE total score, and CGI-S score, and global disease improvement on the CGI-I in adults with BED following pharmacologic treatment, ${ }^{16-20}$ none of these studies described the relationships between these measures at baseline or at study endpoint. As such, the current analyses are novel and help place baseline BE frequency and Y-BOCS-BE total scores, as well as changes in these measures, in a clinical context.

It is important to note that wide score ranges were observed on both CGI-I (0-7 at week 12/ET) and Y-BOCS-BE (8-39 points at baseline; 1-point increase to -36 -point reductions at week 12). This variability may reflect the many different inputs that comprise the evaluation of an individual on these scales. For example, in clinical assessments, differing baseline levels of severity and BE frequency among individuals will result in differing determinations of what constitutes a response that is "very much improved" or "much improved" 
on the CGI-I. Moreover, if BE behaviors are markedly reduced but the obsessive thoughts about $\mathrm{BE}$ persist, the overall CGI-I would also be affected.

When interpreting these analyses, several limitations should be considered. First, these are post hoc analyses based on pooled data from two studies. Therefore, the reported $P$-values are nominal (ie, not adjusted for multiplicity) and should be interpreted with caution. Furthermore, although by convention CGI-S scores $>3$ denote some level of functional impairment, ${ }^{11}$ using the CGI-S as the sole proxy for clinical severity could limit the precision of the findings because specific indices of functional impairment are not taken into account. Potential ceiling effects could also influence the data because relatively few participants were categorized as "severely ill" or "among the most severely ill" on the CGI-S at baseline. Similarly, potential floor effects could influence the data because study entry required a BE frequency $\geq 3$ BE days/week and a CGI-S score $\geq 4$ at baseline. Lastly, a detailed examination of the Y-BOCS-BE subscales was not conducted because the intent of these analyses was to demonstrate broad relationships between total score on a research rating scale, observed behaviors, and general clinical impressions. The approach followed in these analyses is consistent with previous examinations in other psychiatric disorders. $^{4-7}$ A detailed component analysis of LDX treatment effects is beyond the scope of this paper, but would be of interest to pursue in the future.

\section{Conclusions}

The CGI is a scale that allows clinicians to capture more information than is captured by BE frequency or by means of binge-related obsessive thoughts and compulsive behaviors. Specifically, it allows clinicians to consider the distress level and level of functional impairment of an individual. ${ }^{11}$ These factors are not always captured in formal rating scales, making the CGI an important secondary assessment in clinical studies. The current post hoc analyses in individuals with protocol-defined moderate to severe BED suggest that CGI-S score (an index of global disease severity) positively correlates with baseline levels of BE behavior and with the obsessive and compulsive features of BED, with the equipercentile linking function demonstrating that a CGI-S score of 4 (moderately ill) corresponds to $1.995-4.501 \mathrm{BE}$ days/week and to a Y-BOCS-BE total score of 7.5-21.6. Furthermore, the analyses suggest that CGI-I score (an index of global disease improvement) positively correlates with reductions in the same measures, with the equipercentile linking function demonstrating that a CGI-I score of 1 (very much improved) corresponds to a decrease in BE days/week ranging from 3.502 to 7.005 and to a decrease in Y-BOCS-BE total score ranging from 13.9 to 36.5 points. Taken together, these observations further improve our understanding of the clinical significance of treatment outcomes in BED.

\section{Acknowledgments}

This clinical research was funded by the sponsor, Shire Development LLC (Lexington, MA). Shire Development LLC provided funding to Complete Healthcare Communications, LLC (CHC; West Chester, PA), an ICON plc Company, for support in writing and editing this manuscript at the direction of the authors. Under authors' direction, Madhura Mehta, $\mathrm{PhD}$, Wendy van der Spuy, PhD, and Craig Slawecki, $\mathrm{PhD}$, employees of $\mathrm{CHC}$, provided writing and formatting assistance for this manuscript. Editorial assistance in the form of proofreading, copyediting, and fact checking was also provided by $\mathrm{CHC}$.

\section{Disclosure}

Dr Citrome has served as a consultant for Acadia, Alkermes, Allergan, Eli Lilly, Forum, Intra-Cellular Therapeutics, Janssen, Lundbeck, Merck, Neurocrine, Noven, Otsuka, Pfizer, Reviva, Shire, Sunovion, Takeda, Teva, and Vanda and as a speaker for Acadia, Alkermes, Allergan, Janssen, Lundbeck, Merck, Neurocrine Biosciences, Inc., Otsuka, Pfizer, Shire, Sunovion, Takeda, Teva, and Vanda. Dr Kando is a former employee of Shire and holds stock and/or stock options in Shire; she is currently an employee of Adamas Pharmaceuticals (Emeryville, CA). Dr Bliss is an employee of Shire and holds stock and/or stock options in Shire. The authors report no other conflicts of interest in this work.

\section{References}

1. Vyvanse ${ }^{\circledR}$ (lisdexamfetamine dimesylate) [prescribing information]. Lexington, MA: Shire US Inc.; 2017.

2. McElroy SL, Hudson J, Ferreira-Cornwell MC, Radewonuk J, Whitaker T, Gasior M. Lisdexamfetamine dimesylate for adults with moderate to severe binge eating disorder: results of two pivotal phase 3 randomized controlled trials. Neuropsychopharmacology. 2016;41(5):1251-1260.

3. Citrome L. Lisdexamfetamine for binge eating disorder in adults: a systematic review of the efficacy and safety profile for this newly approved indication - what is the number needed to treat, number needed to harm and likelihood to be helped or harmed? Int J Clin Pract. 2015;69(4): 410-421.

4. Goodman D, Faraone SV, Adler LA, Dirks B, Hamdani M, Weisler R. Interpreting $\mathrm{ADHD}$ rating scale scores: linking $\mathrm{ADHD}$ rating scale scores and CGI levels in two randomized controlled trials of lisdexamfetamine dimesylate in ADHD. Prim Psychiatry. 2010;17(3):44-52.

5. Leucht S, Kane JM, Kissling W, Hamann J, Etschel E, Engel R. Clinical implications of Brief Psychiatric Rating Scale scores. Br J Psychiatry. 2005; 187:366-371.

6. Furukawa TA, Shear MK, Barlow DH, et al. Evidence-based guidelines for interpretation of the Panic Disorder Severity Scale. Depress Anxiety. 2009;26(10):922-929. 
7. Leucht S, Kane JM, Etschel E, Kissling W, Hamann J, Engel RR. Linking the PANSS, BPRS, and CGI: clinical implications. Neuropsychopharmacology. 2006;31(10):2318-2325.

8. Biederman J, Krishnan S, Zhang Y, McGough JJ, Findling RL. Efficacy and tolerability of lisdexamfetamine dimesylate (NRP-104) in children with attention-deficit/hyperactivity disorder: a phase III, multicenter, randomized, double-blind, forced-dose, parallel-group study. Clin Ther. 2007;29(3):450-463.

9. Adler LA, Goodman DW, Kollins SH, et al. Double-blind, placebocontrolled study of the efficacy and safety of lisdexamfetamine dimesylate in adults with attention-deficit/hyperactivity disorder. $J$ Clin Psychiatry. 2008;69(9):1364-1373.

10. Berk M, Ng F, Dodd S, et al. The validity of the CGI severity and improvement scales as measures of clinical effectiveness suitable for routine clinical use. J Eval Clin Pract. 2008;14(6):979-983.

11. Busner J, Targum SD. The clinical global impressions scale: applying a research tool in clinical practice. Psychiatry (Edgmont). 2007;4(7): 28-37.

12. Guy W. Clinical Global Impressions. Rockville, MD: US Department of Health, Education, and Welfare; Public Health Service; Alcohol, Drug Abuse and Mental Health Administration; NIMH Psychopharmacology Research Branch; 1976.

13. Deal LS, Wirth RJ, Gasior M, Herman BK, McElroy SL. Validation of the Yale-Brown Obsessive Compulsive Scale modified for binge eating. Int J Eat Disord. 2015;48(7):994-1004.
14. Goodman WK, Price LH, Rasmussen SA, et al. The Yale-Brown Obsessive Compulsive Scale. I. Development, use, and reliability. Arch Gen Psychiatry. 1989;46(11):1006-1011.

15. McElroy SL, Mitchell JE, Wilfley D, et al. Lisdexamfetamine dimesylate effects on binge eating behaviour and obsessive-compulsive and impulsive features in adults with binge eating disorder. Eur Eat Disord Rev. 2015;24(3):223-231.

16. McElroy SL, Arnold LM, Shapira NA, et al. Topiramate in the treatment of binge eating disorder associated with obesity: a randomized, placebo-controlled trial. Am J Psychiatry. 2003;160(2):255-261.

17. McElroy SL, Guerdjikova A, Kotwal R, et al. Atomoxetine in the treatment of binge-eating disorder: a randomized placebo-controlled trial. J Clin Psychiatry. 2007;68(3):390-398.

18. McElroy SL, Hudson JI, Capece JA, et al. Topiramate for the treatment of binge eating disorder associated with obesity: a placebo-controlled study. Biol Psychiatry. 2007;61(9):1039-1048.

19. McElroy SL, Hudson JI, Malhotra S, Welge JA, Nelson EB, Keck PE Jr. Citalopram in the treatment of binge-eating disorder: a placebocontrolled trial. J Clin Psychiatry. 2003;64(7):807-813.

20. McElroy SL, Kotwal R, Guerdjikova AI, et al. Zonisamide in the treatment of binge eating disorder with obesity: a randomized controlled trial. J Clin Psychiatry. 2006;67(12):1897-1906. 


\section{Supplementary material}

Box SI List of independent ethics committee or institutional review boards

\begin{tabular}{|c|}
\hline ClinicalTrials.gov registry number: NCT0I7I8483 \\
\hline $\begin{array}{l}\text { CEIC H. Univ de La Princesa Dña. Cecilia López García } \\
\text { FIB H. Univ. de La Princesa (I I planta) } \\
\text { Calle de Diego León, } 62 \\
\text { Madrid } 28006 \text {, Spain }\end{array}$ \\
\hline $\begin{array}{l}\text { Copernicus Group IRB } \\
\text { I Triangle Drive, Suite I00 } \\
\text { Durham, NC 277I3, USA }\end{array}$ \\
\hline $\begin{array}{l}\text { Ethikkommission bei der Sächsischen } \\
\text { Landesärztekammer } \\
\text { Schützenhöhe } 16 \\
\text { Dresden } 01099, \text { Germany }\end{array}$ \\
\hline $\begin{array}{l}\text { Ethikkommission zur Beurteilung medizinischer } \\
\text { Forschung am Menschen } \\
\text { Berliner Allee } 20 \\
\text { Hannover } 30175 \text {, Germany }\end{array}$ \\
\hline $\begin{array}{l}\text { Independent Ethics Committeee of Hospital General } \\
\text { Universitario GREGORIO MARAÑÓN } \\
\text { C/Dr Esquerdo 46, Pabellón de Gobierno, Planta baja } \\
\text { Madrid } 28007 \text {, Spain }\end{array}$ \\
\hline $\begin{array}{l}\text { Landesamt for Gesundheit und Soziales } \\
\text { Geschäftsstelle der Ethik-Kommission des Landes } \\
\text { Berlin } \\
\text { Fehrbelliner Platz I } \\
\text { Berlin 10707, Germany }\end{array}$ \\
\hline $\begin{array}{l}\text { McLean Hospital } \\
\text { I I } 5 \text { Mill Street } \\
\text { Belmont, MA 02478, USA }\end{array}$ \\
\hline $\begin{array}{l}\text { National Ethics Committee } \\
48 \text { Av. Santescu Street, District I } \\
\text { Bucharest, Romania }\end{array}$ \\
\hline $\begin{array}{l}\text { The Regional Ethical Review Board in Stockholm } \\
\text { Nobels väg 9, Floor D3 } \\
\text { Stockholm, Sweden I7I } 65 \text { SOLNA }\end{array}$ \\
\hline $\begin{array}{l}\text { Tajemník EK } \\
\text { Etická komise IKEM a TN } \\
\text { Vídeňská } 800 \\
\text { Prague 4- Krč, Czech Republic I40 } 59\end{array}$ \\
\hline
\end{tabular}

(Continued)

\section{Box SI (Continued)}

ClinicalTrials.gov registry number: NCT0I7I8509

CEIC H. Univ de la Santa Creu i Sant Pau

Av. Sant Antoni Ma Claret, 167

Barcelona 08025, Spain

Comitato Etico Indipendente Presso la Fondazione

PTV Policlinico Tor Vergata di Roma

Viale Oxford 81

Rome 00133, Italy

Comitato per la Sperimentazione Clinica dei

Medicinali dell' Azienda Ospedaliero Universitaria

Pisana di Pisa

Via Roma 67

Pisa 56126, Italy

Copernicus Group IRB

I Triangle Drive, Suite 100

Durham, NC 27709, USA

Ethik-Kommission an der Medizinischen Fakultät der

Universität Rostock

St-Georg-Str. 108

Rostock 18055, Germany

Ethikkommission zur Beurteilung Medizinischer

Forschung am Menschen

Berliner Allee 20

Hannover, Germany 30175

Human Research Protection Program

D-528 Mayo Memorial Building

420 Delaware Street SE

Minneapolis, MN 55455, USA

Independent Ethics Committee of Hospital General

Universitario GREGORIO MARAÑÓN

C/Dr Esquerdo 46, Pabellón de Gobierno, Planta baja

Madrid 28007, Spain

Landesamt für Gesundheit und Soziales

Geschäftsstelle der Ethik-Kommission

des Landes Berlin

Fehrbelliner Platz I

Berlin 10707, Germany

McLean Hospital IRB

I I5 Mill Street

Belmont, MA 02478, USA

National Ethics Committee

48 Av. Santescu Street, District I

Bucharest, Romania

University of Cincinnati IRB

University Hall, Suite 300

5I Goodman Drive, P.O. Box 210567

Cincinnati, OH 4522I, USA
Neuropsychiatric Disease and Treatment

\section{Publish your work in this journal}

Neuropsychiatric Disease and Treatment is an international, peerreviewed journal of clinical therapeutics and pharmacology focusing on concise rapid reporting of clinical or pre-clinical studies on a range of neuropsychiatric and neurological disorders. This journal is indexed on PubMed Central, the 'PsycINFO' database and CAS,

\section{Dovepress}

and is the official journal of The International Neuropsychiatric Association (INA). The manuscript management system is completely online and includes a very quick and fair peer-review system, which is all easy to use. Visit http://www.dovepress.com/testimonials.php to read real quotes from published authors. 